\title{
Mathias Wirth
}

\section{Distanz des Gehorsams}

\author{
Theorie, Ethik und Kritik einer Tugend
}

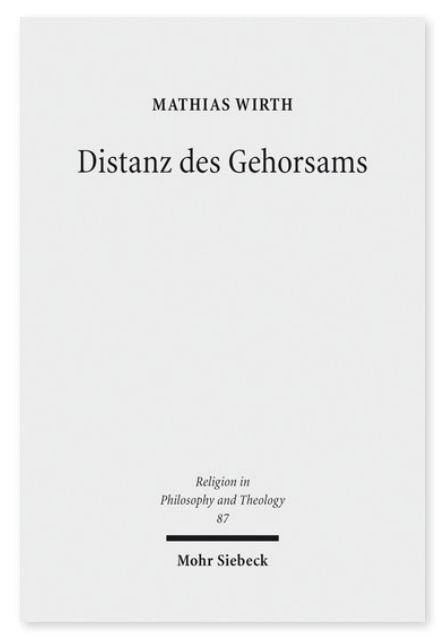

2016. IX, 449 Seiten. RPT 87

ISBN 978-3-16-154956-4

DOI 10.1628/978-3-16-154956-4

eBook PDF 94,00€

ISBN 978-3-16-154086-8

fadengeheftete Broschur 94,00€
Als Tugend beschworen, in Katastrophen geendet: der Gehorsam. Nationalsozialismus, gewaltsame Erziehung, auch in kirchlicher Verantwortung, insgesamt die Diskreditierung der Ich-Instanz in Gehorsamsdiskursen, problematisieren eine Beziehungsform, die bis heute viel diskutiert, aber wenig systematisch untersucht worden ist. In der gefundenen Distanzstruktur des Gehorsams liegt der philosophische und theologische Beitrag dieser Studie zur Erforschung des Gehorsams: Das Problem des Gehorsams ist eine Distanz, die zwischen Person und Akteur, Wollen und Sollen auftritt. Im Gehorsam tun Personen etwas, das sie eigentlich nicht wollen - sonst wäre der Befehl unnötig. Mathias Wirth diskutiert die manchmal auch nur behauptete Distanz zwischen Person und Akteur als ethisches und religiöses Problem.

Diese Arbeit wurde mit dem Wissenschaftspreis Hannover 2014 ausgezeichnet. Außerdem wurde der Studie der Ernst WolfPreis 2017 der Gesellschaft für Evangelische Theologie in der Kategorie A (Dissertationen/Habilitationen) zugesprochen.

Mathias Wirth Geboren 1984; Studium der Ev. Theologie und der Kath. Theologie sowie der Philosophie; 2012-2017 wissenschaftlicher Mitarbeiter am Institut für Geschichte und Ethik der Medizin des Universitätsklinikums HamburgEppendorf; 2014 Promotion. 2017-2018 Feodor Lynen Postdoc an der Yale Divinity School. Seit 2018 Assistenzprofessor (mit tenure track) für Systematische Theologie/Ethik an der Theologischen Fakultät der Universität Bern.

Jetzt bestellen:

https://mohrsiebeck.com/buch/distanz-des-gehorsams-9783161549564?no_cache=1

order@mohrsiebeck.com

Telefon: +49 (0)7071-923-17

Telefax: $+49(0) 7071-51104$ 